\title{
Review
}

\section{Digital Twin Lean Intralogistics: Research Implications}

\author{
Pawel Pawlewski (D), Monika Kosacka-Olejnik*(D) and Karolina Werner-Lewandowska (D) \\ Faculty of Engineering Management, Poznan University of Technology, 60-965 Poznan, Poland; \\ pawel.pawlewski@put.poznan.pl (P.P.); karolina.werner@put.poznan.pl (K.W.-L.) \\ * Correspondence: monika.kosacka@put.poznan.pl; Tel.: +48-616653414
}

\section{check for}

updates

Citation: Pawlewski, P.;

Kosacka-Olejnik, M.;

Werner-Lewandowska, K. Digital

Twin Lean Intralogistics: Research

Implications. Appl. Sci. 2021, 11, 1495.

https://doi.org/10.3390/app11041495

Academic Editor: Piera Centobelli

Received: 14 January 2021

Accepted: 3 February 2021

Published: 7 February 2021

Publisher's Note: MDPI stays neutral with regard to jurisdictional claims in published maps and institutional affiliations.

Copyright: (c) 2021 by the authors. Licensee MDPI, Basel, Switzerland. This article is an open access article distributed under the terms and conditions of the Creative Commons Attribution (CC BY) license (https:/ / creativecommons.org/licenses/by/ $4.0 /)$.

\begin{abstract}
This article presents research implications related to the analysis of current trends occurring in the industry and resulting from the analysis of trends in literature. A new trend is noticeable in the range of computer simulations using digital twin technologies in the optimization of intralogistics processes, the implementation of which is based on Lean philosophy. This article shows the connection of Industry 4.0 with Lean in the context of Digital Twin (simulation) in the area of intralogistics. A three-step methodology of literature research was developed and described. In accordance with the adopted research methodology, research questions were indicated and a detailed list of selection criteria was developed. The research methods included brainstorming and statistical analysis. The research results are presented in three sections: the results of the trend analysis, the results of the quantitative literature research, and the results of the complementary research. The research results confirm the existence of a new trend and form the basis for formulating objectives for further research.
\end{abstract}

Keywords: digital twin; lean; intralogistics; digital twin lean intralogistics

\section{Introduction}

This article presents the effect of research carried out in recent years by the team of authors. The result of the research is the authors' thoughts on new trends and changes in the industry. On the one hand, there is a mechanistic approach by Elon Musk in the production of the Tesla Model 3, which was expressed by excessive automation (too many robots in the final assembly), something that Elon Musk assessed as a mistake [1] "Yes, excessive automation at Tesla was a mistake. To be precise, my mistake. Humans are underrated". On the other hand, there is the Toyota approach, expressed in the book [2]; today's car complexity requires a methodology such as the one developed by Toyota through many decades. Employees are the central focus as they have the best knowledge in the range of production processes. Automation is secondary and should be used to an extent not greater than absolutely necessary. Toyota first tries to understand the production process very well, and only then does it introduce robots into it. In turn, 2011 saw the emergence of an initiative of the German government called Industry 4.0 (shortened to I4.0).

The aim of the article is to present research implications related to the analysis of current trends observed in the industry and resulting from the analysis of trends in the literature. A new trend is noticeable in the range of computer simulations using digital twin technologies in the optimization of intralogistics processes, the implementation of which is based on Lean philosophy.

The main contribution of this paper is to demonstrate the research implications of the new trend referred to by the authors as Digital Twin Lean Intralogistics and justify the need to define it based on the quantitative analysis of literature.

The paper is divided into five sections. Following the introduction, the second section concerns the demonstration of the background of the presented research. It explains the rationale for undertaking research and provides arguments concerning the proposal to introduce the concept of Digital Twin Lean Intralogistics into the terminology. The second 
section presents the existing implications between the concepts of Digital Twin, Lean, and Intralogistics. The third section describes the adopted research methodology for the quantitative review of the literature. The results of the conducted quantitative literature research are presented in section four. The last section presents conclusions and outlines further research.

\section{Related Work}

In learning about complex systems (complexity of details and dynamic complexity), simulation, due to its ability to manipulate space-time, is the only tool that allows us to grasp and understand cause-and-effect relationships distant in time and space and related by frequent feedback (dynamic complexity) [3].

Supply chains and factories are complex and dynamic systems. On the one hand, complexity results from the intricacy of manufactured products and manufacturing technologies. On the other hand, complexity is influenced by the structure of processes implemented in the factory. Dynamics are the effects of changes in the market (requiring changes in the products offered) and internal changes resulting from changes in processes implemented inside factories caused by, for example, changes in the organization of material flows, the introduction of new products, the termination of processes related to products withdrawn from the offer, etc. Figure 1 presents four levels of complexity for the supply chains and factories and the impact of external (market) and internal changes (changes in processes, introduction of new and termination of old processes) on the dynamics of the entire system.

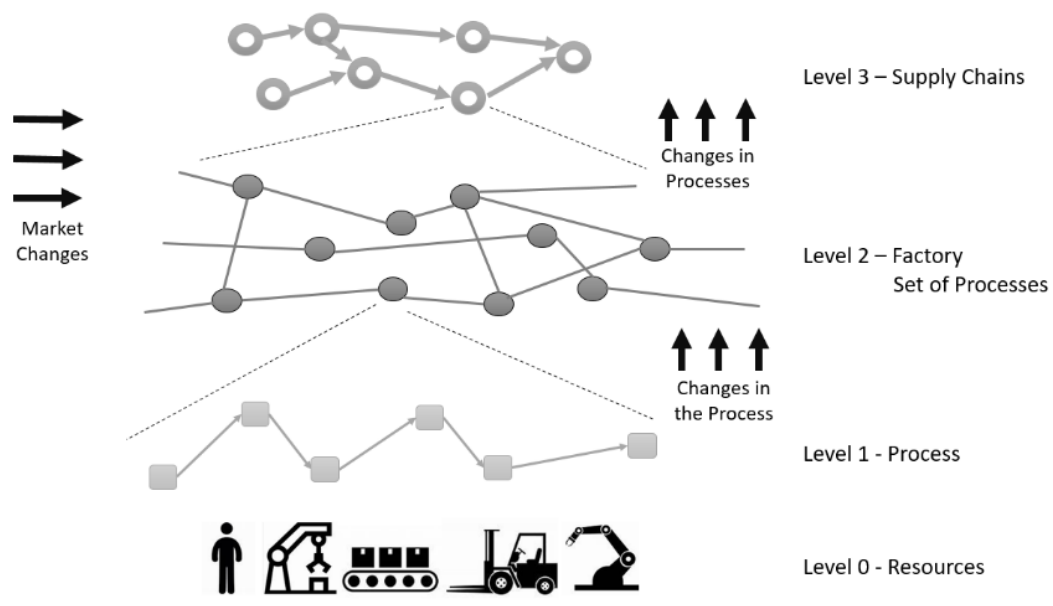

Figure 1. Levels of complexity in supply chains and factories and the impact of external and internal changes on the dynamics of the entire system.

We are now at a time referred to as the industrial revolution 4.0. Industry 4.0., along with the associated involvement of information and communication technologies, is a time for manufacturing companies to think about adapting and changing their current production systems. Industry 4.0 is a general term for various digital concepts such as: the Internet of Things (IoT), the Cyber-Physical System (CPS), Big Data, Data Analytics, Digital Twin, Digital Shadow, Human-Robot Collaboration (HRC), etc. [4]. These concepts promise new potential for production planning and control.

The term "Industry 4.0" was used for the first time in 2011 at the Hannover trade fair in Germany. At this event, the German government presented the I4.0 initiative plan for the first time to protect the long-term competitiveness of the domestic manufacturing industry [5]. A group called the "Industry 4.0 Working Group" was created, chaired by Siegfried Dais (Robert Bosch $\mathrm{GmbH}$ ) and Henning Kagermann (Acatech). The Industry 4.0 concept defines a new organization of factories (called smart factories), enabling better customer service through great flexibility and optimization of resources. 
The key principles for I4.0 are [6]:

1. The factory becomes digital and flexible, which means continuous and immediate communication between various workstations and tools integrated with production lines and supply chains;

2. The use of simulation and data processing tools to collect and analyze data from assembly lines which are used for modelling and testing, which is of great value for employees who want to better understand industrial conditions and processes;

3. Factories become energy-and resource-efficient by using communication networks for the continuous and immediate exchange of information to coordinate needs and availability.

This approach is characterized by a strong link between processes, products, and services represented by the Internet of Things. This concept was widely discussed by scientists and organizations, and its high level of integration creates a working network that connects the physical space and the virtual world via the Cyber-Physical System [7]. In this sense, the I4.0 concept can be interpreted as a strategy to increase competitiveness in the future scenario. It focuses on value-chain optimization because of dynamic and autonomously controlled production [7]. As a result, it facilitates fundamental improvements in industrial processes related to production, material use, supply chain, and life-cycle management. Smart factories, which are already beginning to appear, are adopting a new, productive approach. Intelligent products are uniquely identified. They can be located at any stage of the process and one can learn about their history, current status, and alternative ways to achieve the goal [7].

At the same time, a new term has recently appeared: "Intralogistics". This term is particularly popular in German industries; there are many scientific articles in this area from recognized German universities [8-10]. This term was defined by the Intralogistics Forum Verband Deutscher Maschinen- und Anlagenbau (VDMA) [11] (p. 132) as: "The organisation, control, implementation and optimisation of the internal flow of materials, the flow of information and the handling of goods in industry, retail and public facilities." Other definitions can also be found, e.g., [12]: "Every dimension of logistics within the four walls related to implementing, managing, monitoring and optimizing materials handling and information flows."

Together with the product, process, and layout, intralogistics creates one coherent system in which each element depends on the other. The layout as the central point in this system plays a special role. The layout is a floor plan of the plant that locates equipment according to its functions. It is the integration of the physical arrangement of departments, workstations, machines, equipment, materials, common areas, etc. within the existing or planned enterprise [13].

A change in the product is, for example, a change in the product design, which may result in changing the technology. This, in turn, affects the process structure. The introduction of a new product involves the design of a new process, and the implementation of a new process in the same factory results in changes in layout as well as changes in supporting intralogistic processes. Figure 2 shows three instances of how the situation in the factory has changed: first, three processes P1, P2, P3 were implemented; then, process $\mathrm{P} 4$ was introduced in place of $\mathrm{P} 2$ and $\mathrm{P} 3$, and then process $\mathrm{P} 5$ instead of process $\mathrm{P} 4$, which does not share common positions with process $\mathrm{P} 1$ but uses the same transport infrastructure. The described situation took place in a large factory producing parts for the automotive industry and is characteristic for short series of products.

Another situation is a change in the organization of intralogistic processes based on, for example, forklifts into processes based on logistics trains; the main process remains unchanged while the processes of supplying workstations and receiving finished products change completely. 


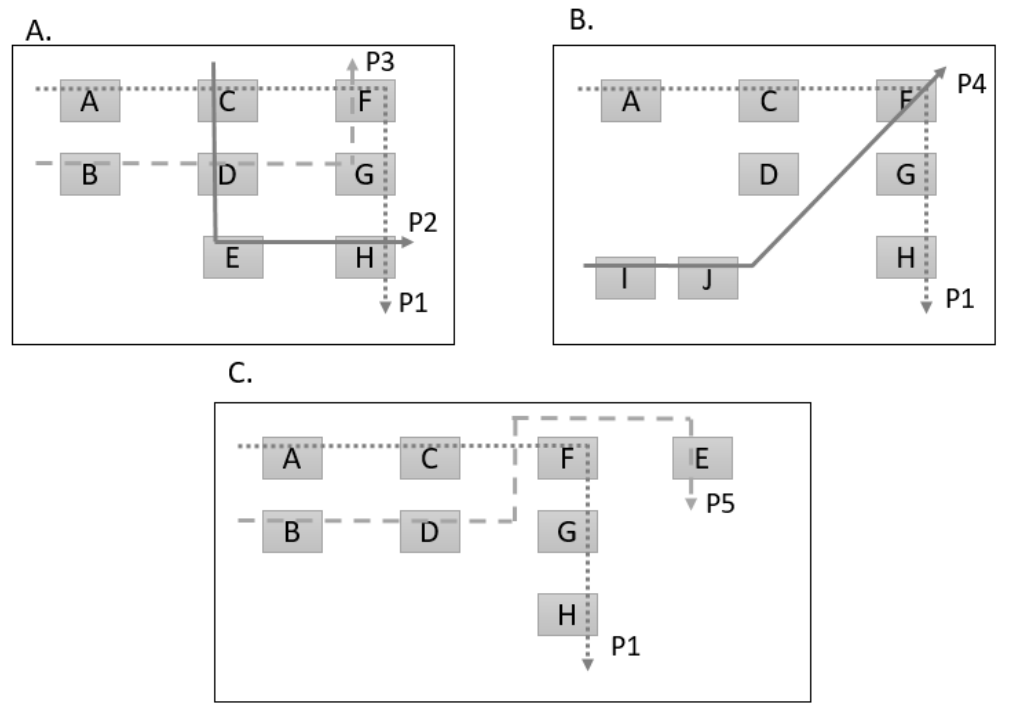

Figure 2. Factory layout dynamics.

Data availability (thanks to the IoT and Digital Twin) makes it possible to increase the efficiency of production planning and control [14]. Lean manufacturing system managers keep asking themselves how to integrate these new opportunities with the existing philosophy and optimization projects. It is currently uncertain whether the I4.0 approach will replace or revive Lean Manufacturing [4]. There are articles whose authors give examples that Lean and I4.0 should be treated complementarily [9,15].

The connection of Lean with I4.0 and the location of simulation regarding intralogistics processes is shown in Figure 3, which is inspired by the siemens.com website [16].

\section{Digital Twin $\quad$ Real World}

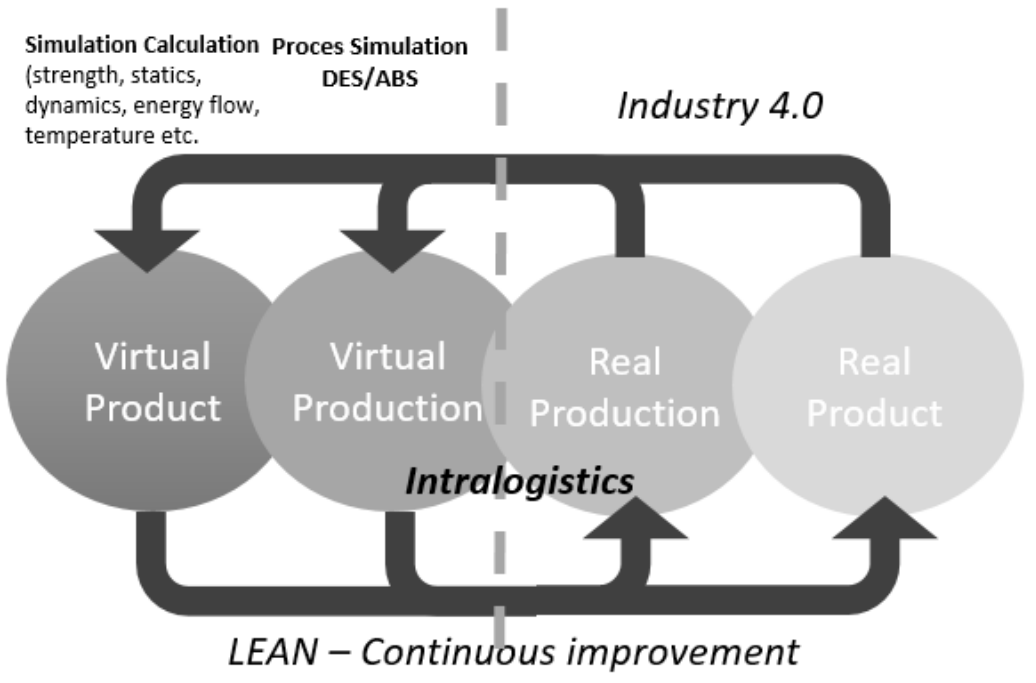

Figure 3. Industry 4.0 and Lean connection in the context of Digital Twin-based on [16].

\section{Methodology}

In this study, the following research methodology was chosen (Figure 4) considering works $[17,18]$.

Referring to Figure 4, a three-stage study was conducted to demonstrate research implications in the range of Digital Twin Lean Intralogistics. 


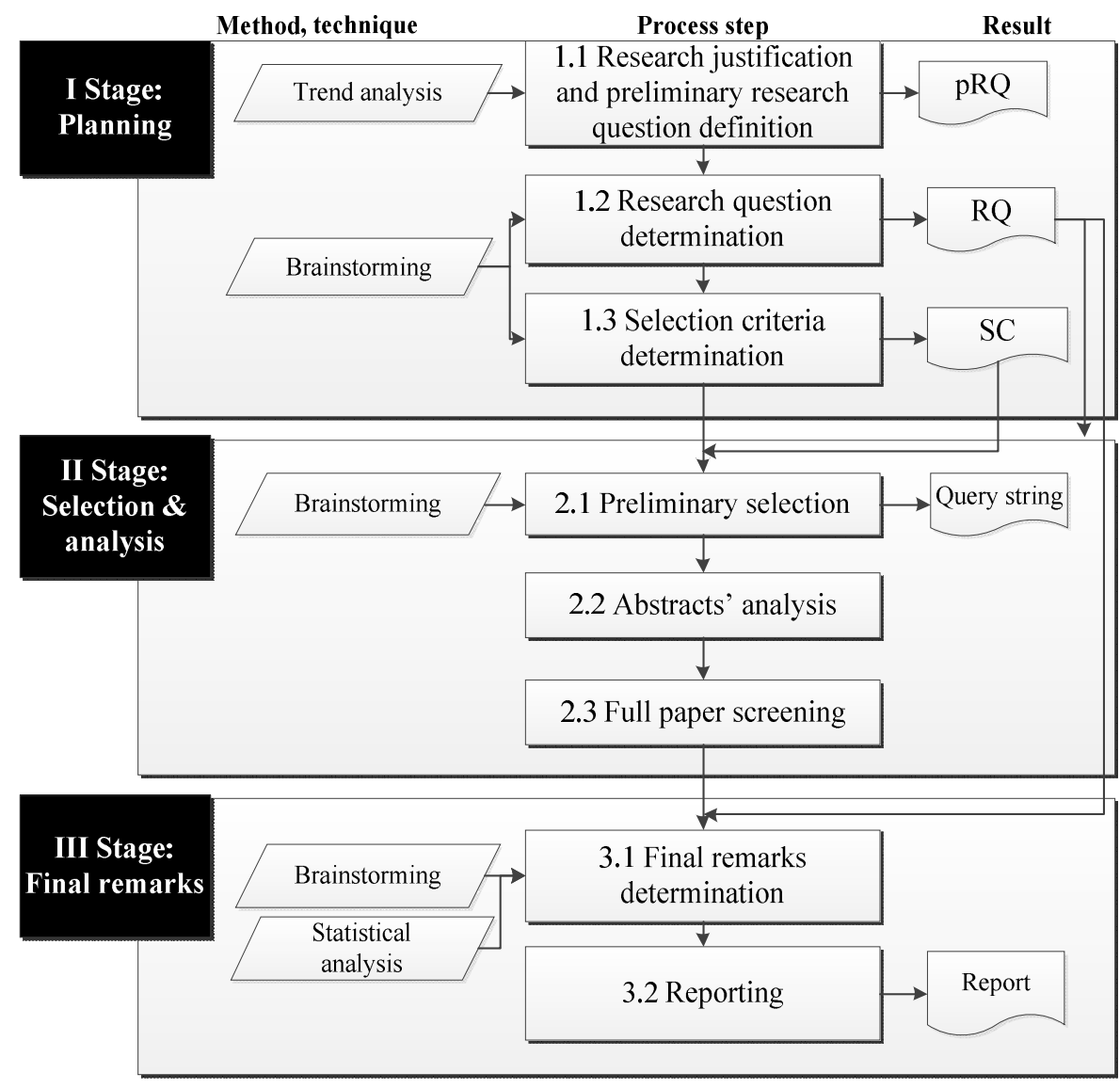

Figure 4. Research methodology.

Stage I: Planning. At this stage, studies were planned that concerned the justification of research on the presented topic (step 1.1.), the determination of research questions (step 1.2.), and the specification of detailed selection criteria (step 1.3.).

In order to justify undertaking research on the implication of the Digital Twin, Lean, and Intralogistics concepts, in accordance with the adopted methodology, a trend analysis was performed. The authors used Google Trends, which allows the analysis of words and phrases entered by users into the Google search engine. The results show the popularity of a search term within a given period and in a selected region. Data in Google Trends are normalized and presented in the range of 0 to 100. Normalization consists of finding the day on which Internet users in a given region and at a given time most often ask for the selected term in the Google search engine (compared to all searches in a given area and time). The obtained result is marked as 100 . The following days are given numbers from 0 to 100 in proportion to the highest score.

In the study related to the analysis of trends, the following preliminary research question was posed (hereinafter referred to as $\mathrm{pRQ}$ ):

- pRQ1: What is the extent of interest in terms such as: "digital twin", "intralogistics", "lean intralogistics", or "digital twin lean intralogistics"?

- $\quad$ RRQ2: Has the digital revolution/Industry 4.0 influenced an increase in interest in digital twin?

The research question pRQ1 results directly from the purpose of the research, while pRQ2 is a kind of derivative question indicating a relationship between I4.0 and Digital Twin technology, which was discussed in Section 2 of the article.

The results of the study of trend analysis allowed the definition of the main research questions according to step 1.2. of the adopted research cycle methodology. It is therefore held that it is justified to conduct a literature analysis related to concepts such as Digital 
Twin, Lean intralogistics, and Digital Twin Lean Intralogistics. After justifying the need for literature research, research questions (RQ) were developed:

- $\quad$ RQ1: Is scientific research related to digital twin being undertaken?

- RQ2: Is research on intralogistics being undertaken?

- RQ2: Is research on lean intralogistics being undertaken?

- RQ3: Is the application of digital twin in intralogistics based on lean philosophy being studied in the range of research on digital twin?

In accordance with the adopted research methodology, in response to the indicated research questions (RQ1-RQ3), a detailed summary of the selection criteria used (hereinafter SC) was developed (step 1.3.). It is presented in Table 1.

Table 1. Selection criteria definition (SC).

\begin{tabular}{|c|c|c|c|}
\hline \multirow{2}{*}{$\begin{array}{c}\text { No } \\
1\end{array}$} & \multicolumn{3}{|c|}{ Selection Criteria } \\
\hline & Keyword & ID & Description \\
\hline & & H1 & $\begin{array}{l}\text { Digital twin, digital-twin, digital twean, } \\
\text { digital-twean, digital twins, digital-twins }\end{array}$ \\
\hline & & $\mathrm{H} 2$ & Intralogistics, intralogistics \\
\hline & & $\mathrm{H} 3$ & Lean intralogistics, lean intralogistic \\
\hline & & $\mathrm{H} 4$ & $\mathrm{H} 1+\mathrm{H} 3$ \\
\hline 2 & Boolean operators & & AND, OR \\
\hline \multirow[t]{2}{*}{3} & Search range & $\mathrm{Z1}$ & Title, abstract, keywords \\
\hline & & $\mathrm{Z} 2$ & Title \\
\hline 4 & Time & & without limitation \\
\hline 5 & Language & & English \\
\hline 6 & Publication type & & without limitation \\
\hline 7 & Research area & & without limitation \\
\hline 8 & Databases & & WoS, Scopus \\
\hline
\end{tabular}

The research used several keywords (H1, H2, H3, H4) which combined issues such as digital twin, intralogistics, and lean, in accordance with the needs expressed in RQ. The keywords were presented in different notation variants. The literature research was planned to be carried out using logical operators AND, OR, making the appropriate combinations of keywords in the title, abstract, or keywords (Z1), or just in the title (Z2). There were no restrictions on the publication date, type of publication, or research area. However, due to the language of publication, searches were limited to English, which stemmed from the assumption that the relevant studies are mainly written in this language.

The abstract and citation databases used in the research included Web of Science and Scopus. The selected databases are mainly used internationally in management studies and are also chosen by online libraries of major universities. In the authors' opinion, these databases proved to be the best in terms of the collection of scientific publications, and provided a great combination of variables, useful for performing the systematic literature review.

Stage II: Selection and Analysis. Three steps were taken at this stage. In the first step, specified as the preliminary selection (step 2.1), query strings for each database were defined considering the required keywords and search range in the frame of the research questions (RQ). The analysis began with a broad approach to the topic (digital twin) in accordance with RQ1. Then, in order to obtain an answer to RQ2, an analysis of publications on the issue of "intralogistics" and RQ 4 "lean intralogistics" was conducted. In accordance with RQ4, publications including the issues of "digital twin lean intralogistics" were also examined. The publications, which were selected in step 2.1, were subjected to an abstract 
analysis. In the next step (step 2.3), the full texts of publications were examined, which, after analyzing the abstracts, were considered to have the potential to obtain answers to RQ2 and RQ3.

Stage III: Final remarks. At the final stage of research, final remarks were defined (step 3.1), which should be associated with research questions (RQ), as shown in Table 2.

Table 2. Quantitative literature review-Research results (as of 12.01.2021).

\begin{tabular}{ccccc}
\hline RQ & Keyword & Search Range & WoS & Scopus \\
\hline RQ1 & H1 & Z1 & 1432 & 2854 \\
& & Z2 & 711 & 1387 \\
\hline RQ2 & H2 & Z1 & 114 & 210 \\
& & Z2 & 46 & 124 \\
\hline RQ3 & H3 & Z1 & 0 & 17 \\
& & Z2 & 0 & 0 \\
\hline RQ4 & H4 & Z1 & 0 & 0 \\
& & Z2 & 0 & 0 \\
\hline
\end{tabular}

In the literature research, the indicated terms $(\mathrm{H} 1, \mathrm{H} 2, \mathrm{H} 3, \mathrm{H} 4)$ were analyzed in a broad context (expressed in Z1) and then narrowed to Z2. Due to the broader context, searching in the $Z 1$ range resulted in better quantitative results (e.g., searching in the $Z 1$ range in the Scopus database gathered 206\% more results than in the Z2 range). However, it was recognized that for issues such as $\mathrm{H} 1$ and $\mathrm{H} 2$, which are general concepts, searches limited to the title of the publication (Z2) garnered better results from the perspective of answering the research questions; these concepts should be included if the publication concerns them. Despite the limitation of the scope of the search for concepts H1 and H2, the number of publications is significant, and that is in spite of the novel character of these concepts. In the case of complex issues expressed in terms $\mathrm{H} 3$ and H4, it was considered worth searching for results in a wider way. After all, for the H3 term, which combined "lean" and "intralogistics", only 17 publications in Scopus were identified and analyzed.

The test results were prepared in the form of a report (step 3.2) in accordance with the research methodology (Figure 4). They are described in Section 4 of the article: Results.

\section{Results}

\subsection{Trend Analysis Results}

In reference to pRQ1, Google Trends was searched to verify global interest in the term "digital twin". The research concerned the period from 1 January 2010 to 12 January 2021. The scope of the study covered the whole world. The results are shown in Figure 5.

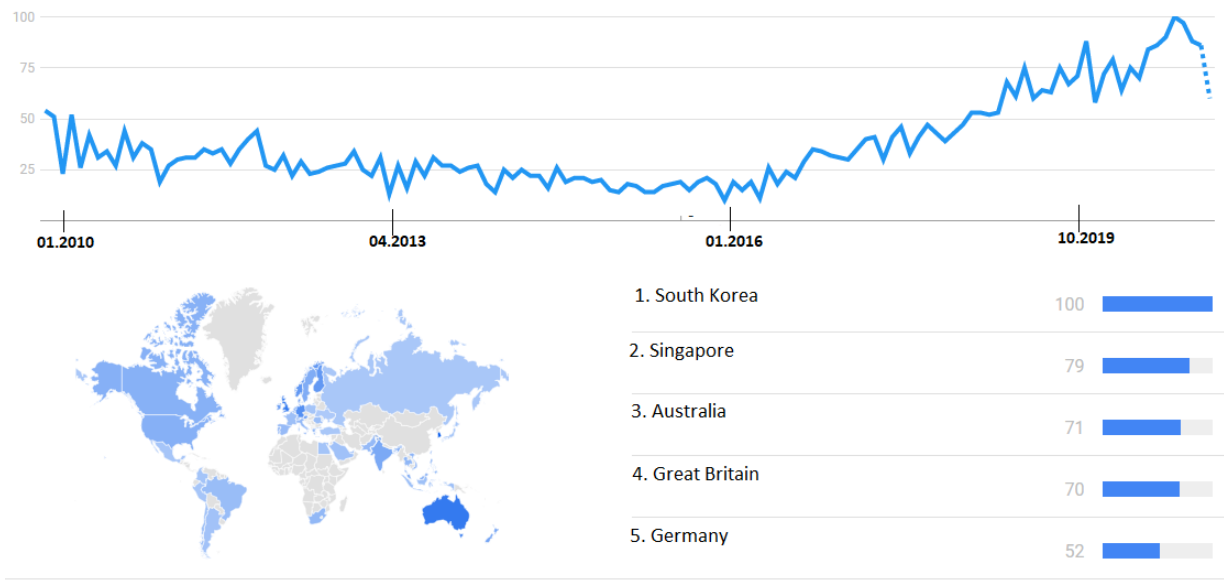

Figure 5. Global extent of interest in the term "digital twin" (concerns the period 1 Jan 2010-12 Jan 2021). 
According to the data in Figure 5, it is noted that interest in digital twin has clearly increased since 2016 and the growing trend may continue. The greatest interest in the term "digital twin", according to Google Trends, occurred in Asia and Europe. The authors link the growing interest in digital twin among Internet users to the birth of the industrial revolution, called the era of the digital revolution Industry 4.0, whose element is digital twin, as mentioned in Section 2 of this article.

The authors expressed this relationship in a research question, $\mathrm{pRQ} 2$. In order to find answers to $\mathrm{pRQ} 2$, the authors examined how trends in interest in the terms "Industry 4.0" and "digital twin" are evolving. Figure 6 shows the results.

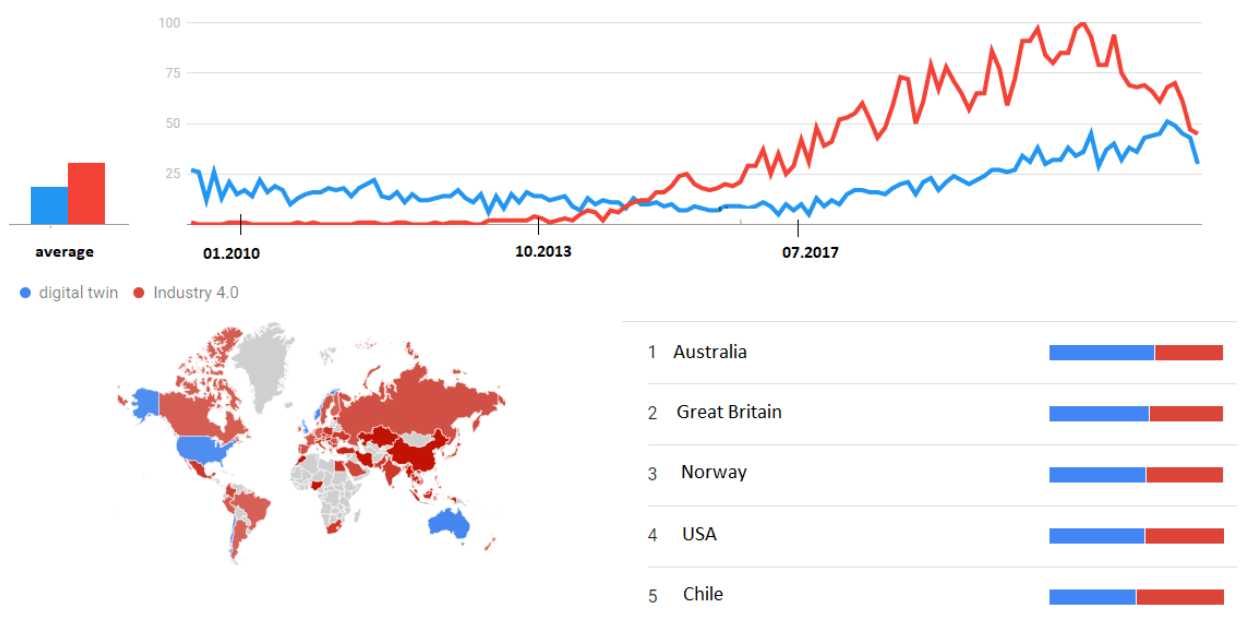

Figure 6. Trends in interest in the terms "Industry 4.0" (red line) and "digital twin" (blue line) (concerns the period from 1 Jan 2010-12 Jan 2021).

The data in Figure 6 clearly indicate that, along with the emergence of interest in Industry 4.0, interest in the term "digital twin" also increased, with the highest level of interest recorded in Australia, Europe and the USA. It is also worth noticing that until 2014 interest in digital twin was higher than interest in I4.0. A detailed explanation of this phenomenon may be the subject of other studies. During the last year, the pandemic situation has changed the global trend, so the interest rate in digital twin as well as in I4.0 has been decreasing. However, when it comes to the relationship between digital twin and I4.0, the authors relate growing interest in digital twin, influenced by the development of I4.0, to the fact that the digital revolution somehow "promoted" or continues to promote IT solutions that are integral to its development. This may be demonstrated by the growing interest of Internet users in the concept of the IoT, the idea of which lies at the heart of the digital age; digital twin solutions are one of the IoT technologies. Figure 7 shows how interest in these terms is shaped.

According to the data in Figure 7, since 2010, the greatest interest among the analyzed trends was related to the Internet of Things, or IoT (these terms mean the same thing, but can be entered in the search engine differently). The greatest interest on a global scale is noted in mostly European countries, as well as in Australia. It is also worth noting that at the time when the IoT reached maximum values according to the Google Trends method, interest in digital twin began to increase. This proves, in the authors' opinion, that Internet users are looking for IT tools and technologies generally called Industry 4.0. Both Digital Twin and IoT are digital technologies that are part of I4.0, but Digital Twin can use IoT (see Figure 3). An increase in IoT possibilities results in an increase in possibilities for monitoring the on-line production process, i.e., an increase in the possibility of reading (collecting) data online and using them directly in Digital Twin. Therefore, in the authors' opinion, one can expect an increased interest in Digital Twin in the coming years as a result of the expansion of the IoT concept. 


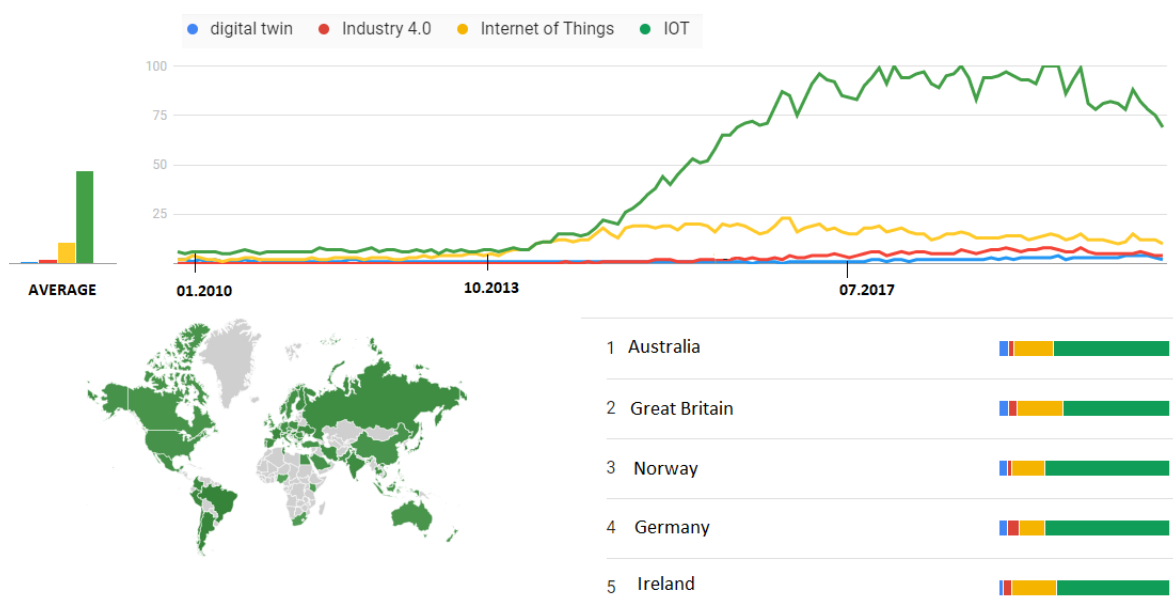

Figure 7. Trends in interest in the terms "Industry 4.0" (red line), "digital twin" (blue line), "Internet of Things" (yellow line), and "IoT" (green line) (concerns the period 1 Jan 2010-12 Jan 2021).

Similar to the study of the term "digital twin", an analysis of the interest-related trend concerning issues such intralogistics, lean intralogistics and digital twin lean intralogistics was made, with reference to $\mathrm{pRQ1}$. Figure 8 shows the global extent of interest in the term "intralogistics".

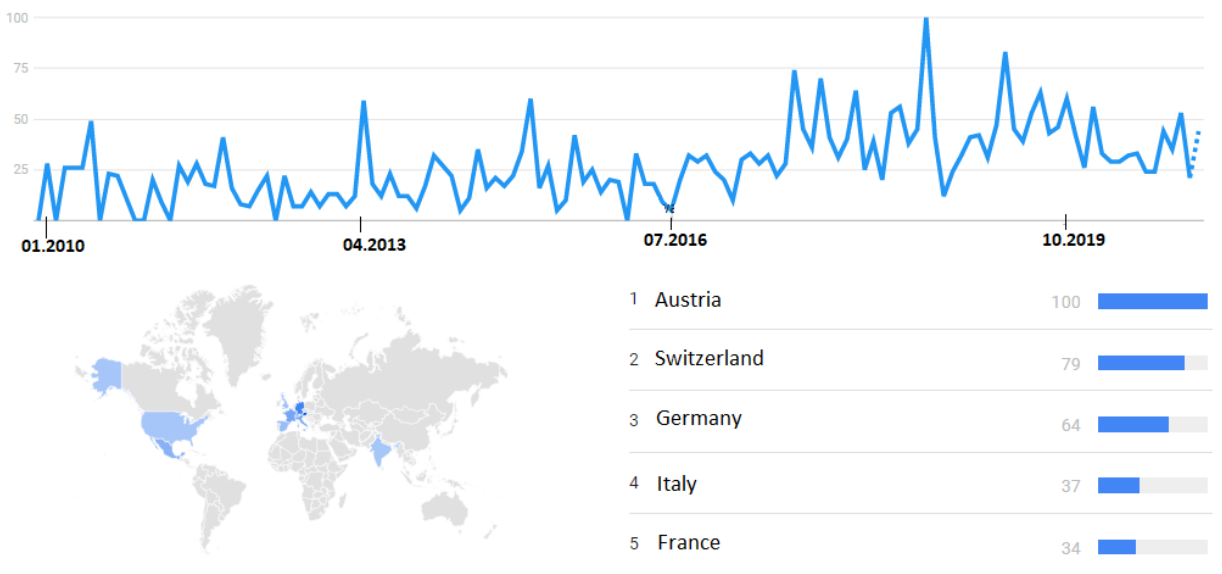

Figure 8. Global trend of interest in the term "intralogistics" (concerns the period 1 Jan 2010-12 Jan 2021).

The data presented in Figure 8 indicate that, since 2010, the trend of interest in the term "intralogistics" has been significantly dynamic, jumping and falling with a simultaneous growing trend that, in the authors' opinion, will continue. It is also worth noting that the term "intralogistics" is most often searched for in Western European countries, including Germany, where originates from, as previously mentioned in Section 2 of the article.

The analysis of trends related to interest in the term "lean intralogistics" showed that, according to Google Trend data since 2010, no one has searched for this term globally in the Google search engine.

After the individual analysis of the trends of each of the analyzed terms, a collective comparison of three terms was made: "digital twin", "lean", and "intralogistics", and the term that is the subject of the article, "digital twin lean intralogistics". The results of the analysis of these terms treated individually are presented in Figure 9. 


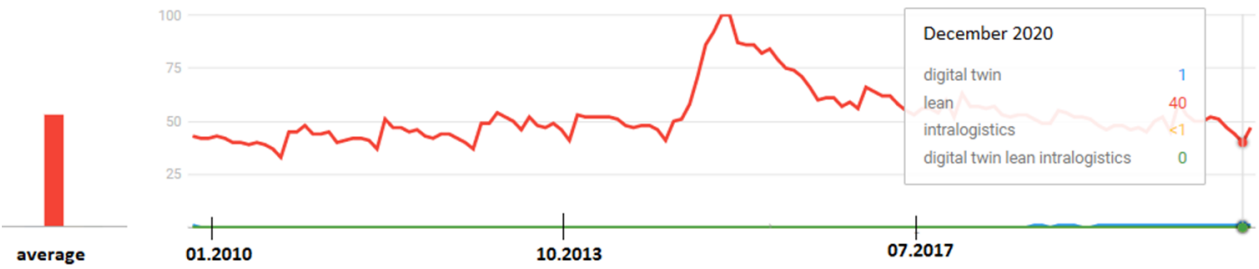

Figure 9. Global interest in the terms: digital twin + lean + intralogistics + digital twin lean intralogistics (concerns the period 1 Jan 2010-12 Jan 2021).

In relation to the whole phrase "Digital Twin Lean Intralogistics", according to Google Trend data, since 2004 such a wording has not been searched for globally on Google.

The compensation of trends in one chart allowed the formulation of answers to pRQ1. The greatest interest among Google users applies to the term "Digital Twin" in comparison with the term "Intralogistics". For both terms, high dynamics and an upward trend are noticeable, which indicates a progressive interest in these areas. Analyzing trends using Google Trend also showed that, until December 2020, the terms "Lean intralogistics" and "Digital Twin Lean Intralogistics" had not been searched for, indicating a research gap.

The conclusion resulting from this part of the research became a premise for continuing studies in the form of quantitative literature research on the issue of digital twin lean intralogistics.

\subsection{Results of the Quantitative Literature Research}

According to the adopted research methodology (Figure 4), quantitative literature studies were performed after the trend analysis. The research was conducted in January 2021. The results of the quantitative literature research related to terms such as "Digital twin", "digital-twin", "digital twin", "digital-twin", "digital twins", "digital-twins" (H1), "Intralogistics", "intralogistics" (H2), "Lean intralogistics", and "lean intralogistics" (H3), and $\mathrm{H} 1$ and $\mathrm{H} 3$ combined are presented in Table 3. The data in Table 3 refer to the number of publications for which, according to Table 2, Z2 was adopted for the search range.

Table 3. Summary of the literature review (12.01.2021).

\begin{tabular}{|c|c|c|c|c|c|c|c|c|}
\hline \multirow{2}{*}{$\begin{array}{l}\text { Keyword } \\
\text { Database }\end{array}$} & \multicolumn{2}{|c|}{ H1 } & \multicolumn{2}{|c|}{ H2 } & \multicolumn{2}{|c|}{ H3 } & \multicolumn{2}{|c|}{ H4 } \\
\hline & WoS $^{1}$ & $S^{2}$ & WoS $^{1}$ & $S^{2}$ & $\operatorname{WoS}^{1}$ & $S^{2}$ & $\operatorname{WoS}^{1}$ & $S^{2}$ \\
\hline till 2014 & 5 & 17 & 8 & 48 & 0 & 0 & 0 & 0 \\
\hline 2015 & 1 & 1 & 1 & 3 & 0 & 0 & 0 & 0 \\
\hline 2016 & 5 & 8 & 3 & 9 & 0 & 0 & 0 & 0 \\
\hline 2017 & 32 & 48 & 5 & 9 & 0 & 0 & 0 & 0 \\
\hline 2018 & 129 & 155 & 8 & 15 & 0 & 0 & 0 & 0 \\
\hline 2019 & 268 & 417 & 17 & 24 & 0 & 0 & 0 & 0 \\
\hline 2020 & 264 & 701 & 4 & 16 & 0 & 0 & 0 & 0 \\
\hline 2021 & 7 & 40 & 0 & 0 & 0 & 0 & 0 & 0 \\
\hline TOTAL & 711 & 1387 & 46 & 124 & 0 & 0 & 0 & 0 \\
\hline first publication & 1973 & 1973 & 2005 & 2004 & & & & \\
\hline $\begin{array}{l}\text { max. number of } \\
\text { papers per year }\end{array}$ & 268 & 701 & 17 & 24 & & & & \\
\hline $\begin{array}{c}\% \text { share of papers } \\
\quad(2019-2020)\end{array}$ & $74.82 \%$ & $80.61 \%$ & $45.65 \%$ & $32.26 \%$ & & & & \\
\hline
\end{tabular}

${ }^{1}$ Web of Science, ${ }^{2}$ Scopus.

Despite the fact that in both WoS and Scopus databases publications whose titles concerned digital twin (H1) or intralogistics (H2) were identified, in the case of "lean intralogistics" or "lean intralogistic", no work meeting the indicated selection criteria was found. 
The term Digital Twin Lean Intralogistics was not identified in either of the databases, regardless of the scope used (Z1 or Z2), which again proves the existence of a research gap in this area.

\subsection{Results of Complementary Research}

Having conducted quantitative literature research related to publications on the concepts studied and done in accordance with the adopted methodology, complementary studies were carried out. Firstly, based on the data from Table 3, tendency in publishing was assessed (see Figure 10). Complementary studies supplement the analysis of trends carried out in the first stage of the research cycle (Planning).

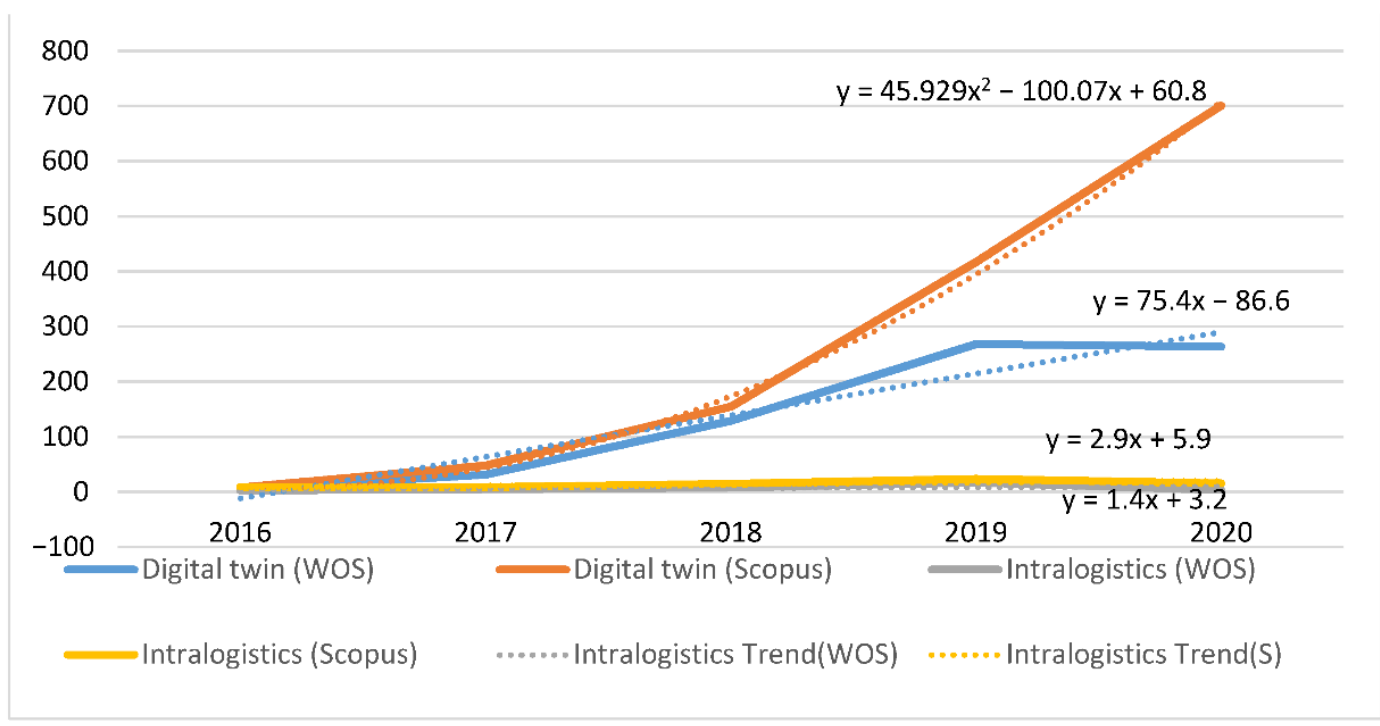

Figure 10. Trends in publications related to terms in $\mathrm{H} 1$ and $\mathrm{H} 2$.

As the results from Figure 10 show, in each case, the function reflecting the trend lines is growing $(\mathrm{a}>0)$, which confirms the growing number of publications related to the research subject. Considering the results of analysis from the last five years (2016-2021) and the trend functions, it is expected that the total number of publications on digital twin will grow to the value of 1114 in 2021 in Scopus and to the value of 366 in WOS. The interest rate on intralogistics should be growing, too, but the growth rate is rather small. As a consequence, it should be noted that digital twin is becoming a highly explored research topic.

Next, correlation between the number of publications related to Digital Twin (H1) and Intralogistics (H2) was examined. To demonstrate the relationship, the Pearson's correlation coefficient rxy was used and the coefficient of determination R2 was calculated. The number of publications related to Digital Twin was adopted as variable $\mathrm{x}$ and the number of publications on Intralogistics was adopted as $y$. The analyses were made separately for publications identified in the Web of Science and Scopus databases. The results are presented in Table 4.

Table 4. Pearson's coefficient and coefficient of determination for the analyzed population of publications.

\begin{tabular}{ccc}
\hline Correlation Coefficients & WoS & Scopus \\
\hline $\mathrm{r}_{\mathrm{xy}}$ & 0.82 & 0.80 \\
$\mathrm{R}^{2}$ & $67 \%$ & $64 \%$ \\
\hline
\end{tabular}


As the data in Table 4 show, there is a positive correlation between publications related to Digital Twin and Intralogistics. Along with an increase in the number of publications in the Digital Twin area, the number of publications on Intralogistics also increased. The analysis did not include 2021 as this is too short a period so far.

\section{Discussion and Conclusions}

The main goal of the article was to demonstrate the research implications of a new trend in computer simulations using digital twin technologies to optimize intralogistics processes, the implementation of which is based on Lean philosophy, named Digital Twin Lean Intralogistics by the authors. According to the authors, this trend is a consequence of current trends noticeable in the industry, as presented in Section 2.

In order to demonstrate the research implications, quantitative literature studies were carried out in accordance with the adopted methodology (Section 3) and the results of these studies (Section 4) indicated a research gap in the area of research on the use of digital twin technology in the optimization of intralogistics processes, the implementation of which is based on Lean philosophy.

Considering the results of individual stages of research, in accordance with the adopted research methodology, as well as the results of complementary studies, the authors conclude that:

1. There is an implication between Digital Twin and Intralogistics, as shown by the results of the trend analysis and the values of the Pearson's coefficient and coefficient of determination. Changes in the number of publications related to intralogistics were $67 \%$ for data from WoS and $64 \%$ for data from Scopus, conditioned by changes in the number of publications related to digital twin. The remaining part of the change results from other factors that were not analyzed. However, it should be remembered that both examined correlation coefficients only focus on the strength and direction of the relationship between the analyzed variables. They do not indicate a causeand-effect relationship. Such a relationship can only be demonstrated through an in-depth qualitative analysis of selected publications. Such analyses are the subject of the authors' further scientific research.

2. Interest in the terms "Digital Twin" and "Intralogistics" is increasing (pRQ1). Both of these issues are also the subject of scientific research, as evidenced by the growing number of publications related to them (RQ2 and RQ3).

3. Growing interest in digital twin technology is determined by the emergence of the I4.0 concept (pRQ2) and related IoT solutions, as confirmed by the trend analysis in Google Trends.

4. There is a research gap in the range of Lean Intralogistics (RQ3), as evidenced by the lack of publications on this subject in the WoS and Scopus databases, undertaking the context of optimizing intralogistics in the spirit of lean philosophy.

5. No publications regarding research on the use of digital twin in intralogistics based on lean philosophy (RQ4) were identified and until 2021 the term "Digital Twin Lean Intralogistics" had not been searched for in the Google search engine.

On the basis of the obtained research results, the authors define a further two-step research direction. The first stage consists of conducting in-depth qualitative literature research on the issue of Digital Twin Lean Intralogistics in order to fully define the term "Digital Twin Lean Intralogistics", extending the scope of research using databases such as IEEE (Institute of Electrical and Electronics Engineers) Explore and IFAC (International Federation of Automatic Control). The second stage consists of developing theoretical assumptions for the Digital Twin Lean Intralogistics concept with a view to its subsequent implementation in a simulation environment and ultimately in industrial reality.

Author Contributions: Conceptualization, P.P. and K.W.-L.; methodology, M.K.-O.; validation, P.P., K.W.-L., M.K.-O.; formal analysis and investigation, P.P., K.W.-L., M.K.-O.; writing-original draft preparation, P.P.; writing-review and editing, M.K.-O., K.W.-L.; visualization, P.P., M.K.-O.; 
supervision, K.W.-L.; funding acquisition, P.P., K.W.-L. and M.K.-O. All authors have read and agreed to the published version of the manuscript.

Funding: This research was funded by the Ministry of Science and Higher Education/Poznan University of Technology, Project ID: 0812/SBAD/4180.

Institutional Review Board Statement: Not applicable.

Informed Consent Statement: Not applicable.

Conflicts of Interest: The authors declare no conflict of interest.

\section{References}

1. Twitter. Available online: https://twitter.com/elonmusk/status/984882630947753984 (accessed on 13 April 2018).

2. Liker, J.K. The Toyota Way: 14 Management Principles from the World's Greatest Manufacturer; McGraw-Hill Education: New York, NY, USA, 2004; ISBN 9780071392310.

3. Cempel, C. Nowoczesne Zagadnienia Metodologii i Filozofii Badań (Eng. Modern Issues of Methodology and Research Philosophy); ITEi: Radom, Poland, 2005.

4. Bauer, H.; Brandl, F.; Lock, C.; Reinhart, G. Integration of Industrie 4.0 in lean manufacturing learning factories. Procedia Manuf. 2018, 23, 147-152. [CrossRef]

5. Hermann, M.; Pentek, T.; Otto, B. Design Principles for Industrie 4.0 Scenarios. In Proceedings of the 49th Hawaii International Conference on System Sciences HICSS, Koloa, HI, USA, 5-8 January 2016; pp. 3928-3937. [CrossRef]

6. Schwab, K. The Fourth Industrial Revolution; Crown Business: New York, NY, USA, 2017; p. 192. ISBN 978-1-5247-5886-8.

7. Kagermann, H.; Helbig, J.; Hellinger, A.; Wahlster, W. Recommendations for Implementing the Strategic Initiative INDUSTRIE 4.0: Securing the Future of German Manufacturing Industry; Final Report of the Industrie 4.0 Working Group; Forschungsunio: Berlin, Germany, 2013.

8. Kartnig, G.; Grosel, B.; Zrnic, N. Past, state-of-the-art and future of intralogistics in relation to megatrends. FME Trans. 2012, 40, 193-200.

9. Schuhmaher, J.; Hummel, V. Self-organization of changeable intralogistics systems at the ESB Logistics Learning Factory. Procedia Manuf. 2019, 31, 194-199. [CrossRef]

10. Trott, M.; Auf der Landwehr, M.; von Viebahn, C. A new Simulation Approach for Scheduling Consolidation Activities in Intralogistics-Optimising Material Flow Processes in Industrial Practice. In Simulation in Produktion Und Logistik herausgegeben von Matthias Putz and Andreas Schlegel; Verlag Wissenschaftliche Scripten: Auerbach, Germany, 2019; pp. 325-334.

11. Hompel, M.; Heidenblut, V. Taschen-Lexikon Logistik; Springer: Berlin/Heidelberg, Germany, 2008; ISBN 978-3-540-28581-6.

12. Intralogistics. Available online: wynright.com/intralogistics (accessed on 21 April 2020).

13. Muther, R.; Hales, L. Systematic Layout Planning, 4th ed.; Management \& Industrial Research Publications: Marietta, GA, USA, 2015; ISBN 978-0-933684-06-5.

14. Oztemel, E.; Gursev, S. Literature review of Industry 4.0 and related technologies. J. Intell. Manuf. 2020, 31, 127-182. [CrossRef]

15. Sanders, A.; Elangeswaran, C.; Wulfsberg, J. Industry 4.0 Implies Lean Manufacturing: Research Activities in Industry 4.0 Function as Enablers for Lean Manufacturing. J. Ind. Eng. Manag. 2016, 9, 811-833. [CrossRef]

16. Drive Optimized Decision-Making: The Closed-Loop Digital Twin with IoT. Available online: https://blogs.sw.siemens.com/ mindsphere/drive-optimized-decision-making-the-closed-loop-digital-twin-with-iot/ (accessed on 21 April 2020).

17. Denyer, D.; Tranfield, D. Producing a systematic review. In The Sage Handbook of Organizational Research Methods; Buchanan, D.A. Bryman, A., Eds.; Sage Publications Ltd.: Thousand Oaks, CA, USA, 2009; pp. 671-689.

18. Kitchenham, B. Procedures for Performing Systematic Reviews; Keele University Technical Report TR/SE-0401; Keele University: Keele, UK, 2004; pp. 1-26. 